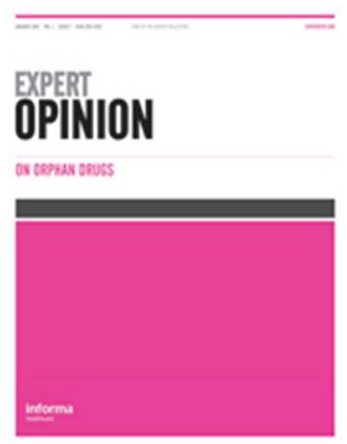

\title{
Pathophysiology, current treatments and future targets in renal Fanconi syndrome
}

\begin{tabular}{|r|l|}
\hline Journal: & Expert Opinion on Orphan Drugs \\
\hline Manuscript ID & EOOD-2016-0107 \\
\hline Manuscript Type: & Review \\
\hline Keywords: & Renal Fanconi syndrome, pathophysiology, proximal tubule, EHHADH \\
\hline \multicolumn{2}{|c}{} \\
\hline
\end{tabular}

SCHOLARONE ${ }^{\text {m }}$

Manuscripts 
Pathophysiology, current treatments and future targets in renal Fanconi syndrome

1

2

3

4

5

6

7

8

9

10

11

12

13

14

15

16

17

18

19

20

21

22

23

24

25

26

27

28

29

30

31

32

33

34

35

36

37

38

39

40

41

42

43

44

45

46

47

48

49

50

51

52

53

54

55

56

57

58

59

60 
Abstract

1 Abstract

Introduction

Renal Fanconi syndrome describes a general dysfunction of the proximal tubules characterised by urinary losses of water, electrolytes, low-molecular weight proteins, amino acids and glucose. The heterogeneity of its underlying causes has complicated the understanding of renal Fanconi syndrome for many years. Recent studies of its isolated form, only affecting the proximal tubule and no other nephron segments, allow new insights into the understanding of pathophysiology and development of disease models.

Areas Covered

In this review, we discuss the most recent insights into pathophysiology of renal Fanconi syndrome as well as novel disease and potential developments of new therapeutic strategies.

\section{Expert Opinion}

The importance of fatty acid oxidation in proximal tubules has just recently been established. So far this has not yet led to pharmaceutical development of medicines, due to lack of understanding of the exclusive use of fatty acids by mitochondria in the proximal tubule for energy generation. Nevertheless, novel insights have resulted in potential targets for development of new therapeutic strategies, including mir21 and mTORC1.

\section{Key words}

Renal Fanconi syndrome, pathophysiology, proximal tubule, EHHADH 


\section{Introduction}

Renal Fanconi Syndrome (RFS) is a generalised dysfunction of the first postglomerular segment, the proximal renal tubule, leading to excessive urinary loss of fluid and solutes. It is named after Guido Fanconi, a Swiss paediatrician who was among the first describing this syndrome in the early 1930s [1] in parallel with De Toni and Debre [2, 3]. RFS might cause massive and life-threatening losses of free water, bicarbonate, sodium chloride and potassium, as well as losses of other freely filtered substances such as phosphate, amino-acids, uric acid, low-molecular-weight (LMW) nutrients and glucose. Many of these valuable solutes can be reabsorbed along the kidney only through the highly specialized proximal tubule epithelial cells [4]. Children might present with failure to thrive, polyuria, polydipsia, dehydration, and rickets, whereas adults might develop osteoporosis and osteomalacia. Clinical features also include renal salt wasting, hypokalaemia, metabolic acidosis and LMW proteinuria [5]. In adults, the renal glomeruli produce more than 150 litres of ultrafiltrate every day, containing approximately 20 mol of sodium (the equivalent of more than $1 \mathrm{~kg}$ of salt) and $>150 \mathrm{~g}$ of sugar $[6,7]$. Normally, approximately $70 \%$ of filtered salt and water and virtually all of filtered sugars, amino acids and proteins are reabsorbed along the proximal tubule [4]. Thus, with complete loss of PT function, up to $120 \mathrm{~L}$ of water and solutes, would be lost per day, indicating the importance of PT function. Complete loss of function is probably not compatible with life and to a degree other nephron segments can compensate, but it is the overspill of water and solutes into the urine that defines the RFS phenotype. 


\section{Maintaining proximal tubule homeostasis}

The enormous reabsorptive capacity is provided by a whole orchestra of specialized apical, basolateral and paracellular transporters driven by the electrochemical gradient generated by the basolateral $\mathrm{Na}+\mathrm{K}+-\mathrm{ATPase}$ (see figure 1). To optimise the reabsorption, cell and transport properties change along the PT. We distinguish three sub-segments, S1-S2-S3, each one lined with different cell types. Moreover, PT cells (mainly S1-S2), express large multiligand endocytic receptors, namely, megalin, cubilin and, perhaps, amnionless that mediate the uptake of the freely filtered LMW proteins [8]. In order to increase the available apical surface area, those PT cells are decorated with differentiated brush borders. The paracellular spaces have a highly dynamic membrane structure: tight junctions, adherens junctions and gap junctions, which play a vital role in epithelial barrier function. Claudin-2 is the main protein responsible for the selective paracellular transport pathway for various ions (mainly sodium) and water $[9,10]$.

\subsection{Proximal tubule controlling the Acid-base balance}

Tight regulation of the extracellular $\mathrm{H}^{+}$concentration is essential for almost all enzyme activity, as alteration in charge might disrupt their function [11]. About $80 \%$ of the filtered $\mathrm{HCO}^{-}$(which is the major buffer in the extracellular fluid) is indirectly reabsorbed by the PT cells. Bicarbonate reabsorption relays on a complicated sequence of events which start at the apical side by active secretion of hydrogen ion through $\mathrm{Na}^{+} / \mathrm{H}^{+}$(isoform 3, NHE3) antiporter, using the electrochemical gradient for sodium uptake into the cell as driving force, which is maintained by the basolateral $\mathrm{Na}^{+} / \mathrm{K}^{+}$ATPase $[7,12]$. In this way, sodium and thus volume homeostasis is molecularly coupled to acid-base homeostasis. The secreted hydrogen ion combines 
with filtered bicarbonate and is the resultant carbonic acid is converted by carbonic anhydrase IV into water and carbon dioxide. The latter diffuses into the proximal tubular cells via aquaporin 1 [13], where hydroxylation occurs to form bicarbonate in the presence of intra-cellular carbonic anhydrase II. Intracellular $\mathrm{HCO}^{-}$is cotransported with $\mathrm{Na}^{+}$at the basolateral membrane via kNBCe1-A in a 1:3 ratio.

Interestingly, plasma $\mathrm{CO}_{2}$ and $\mathrm{HCO}^{-}$at the basolateral membrane appear to be critical for regulation of bicarbonate reabsorption rather than plasma $\mathrm{pH}$ [13].

\subsection{Proximal tubule controlling water and salt balance}

Alterations in sodium balance maintain intravascular volume rather than sodium concentration. Regulation of plasma volume occurs as a response to renal perfusion, as the kidney cannot sense serum sodium. Approximately $60-70 \%$ of the filtered $\mathrm{NaCl}$ is reabsorbed by the $\mathrm{PT}$, which therefore plays a critical role in the regulation of plasma volume and blood pressure. The basolateral $2 \mathrm{~K}+/ 3 \mathrm{Na}+\mathrm{ATPase}$ pump is crucial in generating the electrochemical driving force with low intracellular sodium concentration, high intracellular potassium concentration, which via potassium channels establish a negative intracellular potential difference across the apical and basolateral membranes. The sodium gradient and the intra-cellular electronegativity are the driving force for sodium reabsorption along the apical membrane of the PT. This electrochemical driving force for sodium uptake is utilised for multiple transport processes, such as coupled transport (sodium co-transport with glucose, phosphate, or amino-acids), exchange ( $\mathrm{Na}+/ \mathrm{H}+$ exchanger type $3 \mathrm{NHE} 3)$, and passive diffusion via channels [14]. Water is reabsorbed along with these solutes, as the proximal tubule is fully water permeable due to the constitutive expression of aquaporin 1 water channels. Consequently, the urinary fluid leaving the proximal tubule has the 
same tonicity as the initial glomerular filtrate as solute reabsorption occurs isotonically [5]. In patients with RFS there is impaired reabsorption of sodium and other solutes, as well as water in the proximal tubules leading to hypotension and dehydration. Increased delivery of sodium to the distal tubules, as well as the hypovolaemia, activates renin-angiotensin system, which leads to potassium wasting in the distal tubules and to clinical hypokalaemia as a consequence.

\subsection{Proximal tubule controlling phosphate reabsorption}

Under physiological conditions, around $80 \%$ of the freely filtered phosphate $(\mathrm{Pi})$ is reabsorbed along the proximal tubules mainly along the convoluted segment. The involved Pi transporters (mainly $\mathrm{NaPi} / \mathrm{la}, \mathrm{NaPi}$ Ilc) are secondary-active sodium phosphate co-transporters, confined to the apical brush border membrane. Tubular Pi reabsorption is controlled by a number of hormones (parathyroid hormone, 1,25dihydroxyvitamin D3, FGF-23, glucocorticoids) and metabolic factors (phosphate loading, metabolic acidosis), by changing the apical expression of $\mathrm{Na}+\mathrm{Pi}$ cotransporters at the brush border membrane $[15,16]$.

Most of the patients with RFS present with low tubular reabsorption of phosphate $(<80-85 \%)$ and decreased serum phosphate. Of note, with very low plasma phosphate levels, the reabsorptive capacity of the PT may keep up reabsorption with this decreased filtered phosphate load, so that TRP can be normal in RFS. For this, reason, the TmP/GFR (= SP-UP $\times$ SCr:UCr) is a better tool to assess renal phosphate handling [17]. Rickets in children and osteomalacia in adult are secondary to the increased urinary wasting of phosphate and impaired 1-alfa hydroxylation of vitamin D (see below). 


\subsection{Proximal tubule controlling LMW protein reabsorption}

The glomeruli filter significant amounts of protein into the primary human urine, yet the finally excreted urine is almost entirely protein-free. The glomerular filtration membrane retains proteins larger than about $60 \mathrm{kDa}$, with some exceptions, such as albumin $(66 \mathrm{kDa})$ and transferrin $(81 \mathrm{kDa})$, which pass through to some extent [18]. In the kidney, the proximal tubule is the only nephron segment involved in the reabsorption of LMW proteins. The renal proximal tubule reabsorbs almost the entire physiologically filtered protein load, including albumin and LMW proteins. LMW proteins and albumin are reabsorbed via a luminal receptor mechanism. The active processes by which the renal proximal tubule reabsorbs filtered plasma proteins, vitamins, vitamin-binding proteins, and hormones are vital for body homeostasis and take place mainly in the first two segments of the proximal tubule [8]. The apical cubilin-megalin complex plays an essential role in this process [19]. The three promiscuous receptors, megalin, cubilin and amnionless, cooperate in the proximal tubule in order to reabsorb nearly all filtered plasma protein. They work in concert notwithstanding their considerable structural differences. In RFS, proteinuria, which can be within the nephrotic range, is predominantly caused by the dysfunction of protein reabsorption in the proximal tubules [20].

\section{Proximal tubule and vitamin D metabolism}

Vitamin D, a lipid, is mostly bound to a specific carrier protein in plasma, vitamin D binding protein (VDBG). VDBG is a LMW protein, that is filtered by the glomerulus and then reabsorbed in the proximal tubules via megalin. In this way it becomes available for the critical activation step of 1-alfa hydroxylation, which occurs in the PT mitochondria. 


\section{Disease model}

\subsection{Part of multisystem metabolic diseases causing accumulation of toxic metabolites}

\subsubsection{Cystinosis}

Cystinosis is an autosomal recessive lysosomal storage disorder caused by mutations in the CTNS gene coding for the lysosomal cystine/proton transporter cystinosin. It is characterized by the accumulation of cystine in all organs, mainly kidney, cornea, bone marrow, thyroid, lymph nodes, liver and spleen [21] . It is the most common cause of inherited RFS in children with an estimated incidence of 0.51.0 per 100000 live births [22]. There are three main clinical forms described depending on the age of onset and severity of disease: Infantile, juvenile or adult form [23]. The infantile (nephropathic) form is the most severe and most common $(95 \%)$ form leading to symptoms of renal RFS during the first year of life. Patients may also develop severe rickets and growth retardation due to phosphaturia. At onset patients usually have normal kidney function, but progress to end stage kidney disease (ESKD) around the age of 10 years if no adequate treatment is provided. The juvenile (nephropathic) form and the adult (non-nephropathic) form are less severe and less common. Patients with the juvenile form present with milder forms of RFS with later progression to renal failure, whereas the adult form is characterized by isolated corneal cystine crystal deposition [24].

Pathophysiology

Current evidence shows that cystinosis is a monogenic-recessive disease with complete penetrance. The underlying bi-allelic mutations are located in the CTNS gene encoding the lysosomal cystine transporter cystinosin. The gene consists of 12 
exons and the most common mutation ( $>70 \%$ in Caucasians) is a $57 \mathrm{~kb}$ deletion, which includes the first nine exons and a part of exon 10 of the CTNS gene $[1,25]$. The mutation also involves the adjacent CARKL gene and the first two non-coding exons of the TRPV1 gene. However, no clinical correlation has been reported so far with the CARKL and TRPV1 genes in affected patients [26], except for perhaps an increased tolerance to spicy food. More than 100 mutations in the CTNS gene are described with novel mutations still being reported $[27,28]$. The differences of the clinical phenotype in the different forms are explained by more severe mutations in both alleles in the infantile cystinosis versus milder mutations in the juvenile and adult form.

The CTNS gene codes for cystinosin, which is a 367 amino acid protein with seven transmembrane domains . It functions as a proton/cystine co-transporter and is driven by the high proton content within the lysosomal lumen. A defect in the transport mechanisms causes accumulation of cystine in the lysosomal lumen with formation of cystine crystals and cell atrophy [29]. The mechanistic links between lysosomal cystine accumulation and the development of RFS have been studied in several in vitro studies but still remain not fully understood [30]. A recent Ctns-/- mice study provided some insight into the pathophysiology by showing that lysosomal cystine inclusion leads to apical proximal tubular cell (PTC) dedifferentiation with reduced expression of multi-ligand megalin and cubilin receptor and $\mathrm{NaPi}-\mathrm{Ila}$, followed by PTC atrophy [31]. It has been shown that lesions start developing in segments adjacent to the glomerulotubular junction and then extend longitudinally along the proximal tubulus. This explains proximal tubular cell flattening, also referred as "swan neck lesions", the typical finding seen in biopsies from cystinotic children [32, 33]. 


\section{Clinical presentation and diagnosis}

Clinical symptoms of RFS in the infantile form are heterogeneous. Affected children generally present early and manifest symptoms at the age of 6-12 months. Presenting symptoms are polyuria, polydipsia, dehydration, fluid and electrolyte loss, aminoaciduria, glucosuria, proteinuria, failure to thrive and/or rickets. Development of ESKD depends on the age of treatment initiation [34]. Diagnosis is usually confirmed by elevated cystine levels in peripheral leukocytes along with corneal cystine crystals demonstrated by the split lamp exam and consecutive genetic analysis of the CTNS gene.

Treatment

Fluid and electrolyte management is the main supportive therapy in patients with Fanconi syndrome secondary to cystinosis. Additionally, the supplement of oral cysteamine, a cystine-depleting agent, is crucial in the treatment for cystinosis [3539]. Early initiation of cysteamine treatment has been proven to delay the progress of ESKD and should be provided to every patient with the diagnosis of cystinosis. A new treatment target, transcription factor EB (TFEB) has been suggested recently. TFEB activates the transcription of different proteins involved in the cell clearance and has been shown to promote clearance of cystine storage in cells within $24 \mathrm{hrs}$ and might also lead to a rescue of the lysosomal compartment of cells affected by cystinosis [40].

\subsubsection{Fanconi-Bickel syndrome}

Pathophysiology 
Fanconi-Bickel syndrome (FBS) is an autosomal recessive disease of carbohydrate metabolism caused by mutations of the GLUT2 gene (also referred as SLC2A2) coding for a glucose transporter in hepatocytes, pancreatic beta-cells, enteral cells and renal tubular cells [41]. Over 34 different mutations have been reported. These mutations included missense, nonsense, frameshift and splice-site mutations, scattered over the whole coding sequence of SLC2A2 gene and with none of those mutations being particularly frequent $[41,42]$.

\section{Clinical presentation}

FBS is characterized by hepatomegaly and nephromegaly caused by glycogen accumulation. Further, impaired utilization of glucose and galactose leads to fasting hypoglycemia and postprandial hyperglycemia, combined with galactose intolerance and development of Fanconi syndrome, rickets and severe short stature [43].

\section{Treatment}

Therapy is mainly supportive and focuses on maintaining glucose homoeostasis, with frequent feeding including night-time. Moreover, treatment should aim to compensation of renal solute losses including sodium bicarbonate, potassium and phosphate supplements.

\subsubsection{Tyrosinemia type I}

\section{Pathophysiology}

Tyrosinemia type 1 is an autosomal recessive disease of the amino acid metabolism caused by a mutation in the fumarylacetoacetate hydrolase $(F A H)$ gene coding for the last enzyme in the tyrosine catabolic pathway, which catabolizes the conversion of fumarylacetoacetate (FAA) into fumarate and acetoacete. FAH is mainly expressed in the liver and kidney, where lack of FAH causes accumulation of toxic 
metabolites such as maleylacetoacetate (MAA) and fumarylacetoacetate (FAA) and their derivates succinylacetone, leading to progressive liver disease and RFS [44]. The accumulation of those metabolites disrupt the sulfhydryl metabolism by forming glutathione adducts which makes cells more vulnerable to free radical damage. Further FAA and MAA are known mutagens and can promote cell apoptosis [44]. As a response to those intracellular effects hepatic and renal cells developing cell apoptosis or mutation if they are exposed to high levels of FAA or MAA. In the kidney that leads to glumerulosclerosis and interstitial fibrosis [45]. Symptoms include progressive hepatic dysfunction beginning in early childhood with progression to cirrhosis and hepatocellular carcinoma. Kidney involvement is represented by the development of RFS and hypophosphatemic rickets.

\section{Clinical presentation and diagnosis}

Clinical symptoms can be related to progressive liver damage with reduced coagulation factors, hypoglycemia and acute hepatic crisis such as ascites, jaundices and gastrointestinal bleeding. One third of the patients will develop liver cancer [46]. In regards to the renal involvement, patient show abnormal renal architecture (increased size and echogenicity on renal ultrasound) and development of tubular dysfunction including hypophosphatemic rickets with hypercalciuria, generalized aminoaciduria, renal tubular acidosis and mild proteinuria. Glycosuria is less common due to in general low blood glucose levels.

Diagnosis includes confirming elevated levels of succinylacetone in plasma and urine. Plasma tyrosine and methionine levels are usually elevated in untreated patients.

Treatment 
First line treatment includes a low phenylalanine and low tyrosine diet and early treatment with NTBC [2-(2-nitro-4-trifluoro-methylbenzyol)-1,3-cyclohexanedione] an inhibitor of 4-hydroxyphenylpyruvate-dioxygenase. NTBC has been shown to prevent the accumulation of fumarylacetoacetate and its conversion to succinylacetone, and can rapidly improve tubular function in patients with Tyrosinemia type 1 , leading to significant improvement of proteinuria and mean plasma phosphate levels $[44,47]$.

\subsubsection{MODY 1}

Recently, RFS has been described in association with MODY 1 (maturity onset diabetes of the young type 1) caused by a heterozygous mutation R63W (previously annotated as R76W) in the HNF4A gene [48]. Different mutations in the HNF4A gene have been described to cause neonatal hyperinsulinism followed by decreased insulin secretion later on in live. Why only this particular dominant mutation also causes RFS remains to be investigated [6].

\subsubsection{Others}

Other genetic forms of RFS include Galactosemia, an autosomal recessive disease of the galactose metabolism caused by deficiency of galactose-1-phophate uridyltransferase (GALT). Patients normally present in the neonatal period after first intake of galactose with severe symptoms including lethargy, jaundice, liver disease, sepsis, cataract and RFS [49].

Wilsons disease, an autosomal recessive inborn error of copper metabolism caused by defects in the copper-transporting P-type ATPase beta-polypeptide (ATP7B) with reduced ceruloplasmin synthesis and biliary excretion of copper. 
Patients develop progressive liver disease, progressive neurological disorders and RFS $[50,51]$.

Hereditary fructose intolerance, an autosomal recessive disorder with deficiency of aldolase B which catalyses the metabolism of fructose and leads to an inability to metabolize fructose. Patients presents with vomiting, hypoglycemia, hypophosphatemia, hyperuricosuria, hyperuricemia and growth retardation $[51,52]$.

\subsection{Disruption of endocytosis and intracellular transport}

\subsubsection{Lowe syndrome}

Oculo Cerebro Renal Syndrome of Lowe (OCRL) is an X-linked recessive multisystem disorder characterised by congenital cataracts, intellectual disability, and renal tubulopathy (OMIM 309000). Lowe syndrome results from loss-of-function mutations in OCRL which encodes phosphatidylinositol 4,5-bisphosphate 5phosphatase (Ptdlns(4,5)P2 5-phosphatase) [53]. In humans, this enzyme is expressed primarily in the kidney, brain, and eyes, which are consequently the main organs affected by OCRL syndrome $[54,55]$. Localisation of the OCRL enzyme to the endosomal apparatus suggests that it may play a role in intracellular trafficking, sorting, and recycling of apical membrane multi-ligand receptors megalin-cubilin [5658]. The precise molecular link between the OCRL enzyme and receptors on the cell surface remains elusive $[59,60]$. Treatment is symptomatic due to absence of efficient therapy [61].

\subsubsection{Dent disease}

Dent 1

Dent disease is an X-linked recessive disease, often associated with progressive kidney function impairment. The first identified causative gene was CLCN5 
(Xp11.22) (Dent 1 disease), which accounts for approximately 60\% of reported pedigrees. CLCN5 is a chloride/proton anti-porter that works together with the electrogenic H+-ATPase to achieve endosomal acidification, which is a crucial step in normal endosomal function [62]. Loss-of-function mutations of CLCN5 result in hypercalciuria, nephrolithiasis, metabolic acidosis, aminoaciduria, glycosuria, hypophosphatemic rickets due to hyperphosphaturia, and LMW proteinuria [63]. Norden et al. [64] found a striking deficiency of urinary megalin protein in Dent's disease patients compared with normal controls. They concluded that reduced shedding of megalin receptor from the apical membrane to the urine flow reflects the abnormal recycling of the receptor back to the apical membrane. This defect would interfere with the normal endocytic function of megalin, resulting in losses of potential ligands into the urine and leading to tubular proteinuria.

\section{Dent 2}

Investigations in families with Dent disease in whom CLCN5 mutations had been excluded led to the surprising discovery of mutations in OCRL, the gene previously identified as the cause of Lowe syndrome. Mutations in this gene account for about $15-20 \%$ of cases of Dent's syndrome and these are now referred to as Dent 2 disease $[54,65]$. The cause for the pleiotropy of OCRL is not fully elucidated, although there is some genotype-phenotype correlation in that the vast majority of Dent 2 mutations are located on exon 9, whereas mutations causing Lowe syndrome are typically located in exon 8-23 [66]. Nevertheless, there is no clear separation with nonsense mutations with assumed complete loss of function found in both Dent 2 and Lowe patients. These phenotypes are now believed to be two ends of a phenotypic spectrum [67]. Bockenhauer et al. [56] investigated eight boys with Dent 
2. All had LMW proteinuria and hypercalciuria, but none developed renal tubular acidosis. Hoopes et al. reported on five families with a similar phenotype [65].

The care of patients with Dent's disease is supportive, focusing on the prevention of nephrolithiasis [63].

\subsection{Genetic renal Fanconi syndrome}

Three genetic forms of renal Fanconi syndrome have been described: Fanconi renotubular syndrome FRTS types $1-3$.

\subsubsection{FRTS1}

The first form has been mapped on chromosome 15, although the gene has not been identified yet [68]. FRTS 1 is also associated with progressive chronic kidney disease, but the underlying mechanism remains unknown and as such no therapeutics are available yet.

\subsubsection{FRTS2 - SLC34A1}

FRTS2 is caused by homozygous in-frame 21 bp duplications in SLC34A1, which codes for the phosphate transporter NAPi-Ila [15]. It has only been reported in few patients so far $[15,69]$. The phenotype is dominated by phosphate wasting and rickets despite high $1,25 \mathrm{OH}$ vitamin $\mathrm{D}$ levels. Interestingly not all proximal tubular functions are affected and renal tubular acidosis was not present in the reported cases. However, the underlying mutation in SLC34A3 has been described before to cause hereditary hypophosphatemic rickets with hypercalciuria [70]. Mutations in SLC34A1 are now recurrently identified in patients with infantile hypercalcaemia [71]. The reason for this pleiotropy is again poorly understood but for the RFS, the 
underlying mechanism has been proposed to be intracellular phosphate depletion leading to insufficient ATP generation [6].

\subsubsection{FRTS3 - EHHADH}

The third form is an isolated full blown RFS caused by heterozygous missense mutation in a gene called EHHADH first described by Klootwijk et al. [72]. The phenotype presents as isolated Fanconi syndrome with no progression to chronic kidney disease. An interesting aspect of this disease is the realisation that despite lifelong loss of water and solutes glomerular kidney function is preserved. The disease mechanism has been identified as a dominant negative effect from intracellular mistargeting of the mutated enzyme $[72,73]$. Whilst the enzyme (and thus the mutation in patients) is expressed ubiquitously, symptoms only manifest in the proximal tubule. The reason for this is the dependency on fatty acid metabolism for energy generation in the proximal tubule [74]. EHHADH interferes with a mitochondrial enzyme that is involved in mitochondrial fatty acid oxidation and has a high degree of homology to EHHADH. So the erroneous assembly of mutant mislocalised EHHADH into this enzyme leads to a defect in ATP production causing RFS. In other tissues, glucose can be metabolised and ATP generation is thus not affected [6].

\subsection{Acquired forms of renal Fanconi syndrome}

Multiple drugs have been described to cause tubular damage and consequently RFS. Those include HIV therapy, heavy metals (cadmium/lead administration), antibiotics, valproic acid as well as exogenous factors as glue sniffing and exposure to suramin, fumaric acid, or ifosfamide $[75,76]$. Most of those drugs are freely 
filtrated in the glomerulus and reabsorbed in the tubules, where they interfere with different parts of the proximal tubules [77].

Further RFS has been described in association with monoclonal gammopathies (adult) nephrotic syndrome, Sjörgen syndrome and others [78-81].

\section{Expert opinion}

The clinical experience leading the research of the last decades has partially unravelled the pathogenic mechanisms leading to different forms of RFS. Thus, the common element involved in the heterogeneous nature of RFS, including from acquired to different genetic causes, with seemingly different molecular pathologies, is the dysfunction of a cellular organelle, mitochondria.

The renal toxicity of some of the therapeutic agents including anti-retroviral therapeutics, and the anti-epileptic valproic acid [82] has been intensively discussed even though the pathologies for these acquired RFS forms are not completely deciphered [6, 82-84]. The key findings in the field of RFSs focused on identification of mono-genetic causes [72, 84]. A recent study about a large mono-genetic RFS family validated mitochondria's role by showing defective fatty acid oxidation due to a particular mutation $(E 3 K)$ in EHHADH. Surprisingly this mutation resulted in mistargeted EHHADH resulting in disruptive formation of the mitochondrial trifunctional protein complex now encompassing the mutated EHHADH. These findings provide new clues for treatment of this type of renal Fanconi syndrome (FRTS3), and other RFS as well.

Future therapeutic strategies could be directed in strengthening or protecting the mitochondria against toxic substances either through controlling the import of 
proteins to mitochondria or through therapeutically targeting mitochondrial fatty acid oxidation in RFS (Figure 2). In contrast with the findings related to fatty acid oxidation, apoptosis has been for a long time associated with certain types of RFS [85].

All these future therapeutic strategies for treatment of RFS that came to existence due to novel research findings in identification of the patho-mechanistic nature of RFSs will be discussed in the next few paragraphs.

\subsection{Potential Treatment options}

\subsubsection{Targeting protein import problems in ATP deficiency related RFS}

FRTS3 patients have been shown to have a fatty acid accumulation problem leading to a decreased ATP production $[72,73]$. In order to address the fatty acyl accumulation problem in FRTS3, the import of the causative mutated protein could be prevented by using the FDA approved drug Dequalinium chloride (DECA), recently shown to be effective in restoring mitochondrial function in a cell model for primary hyperoxaluria I [86]. The agent DECA holds great promise as a therapeutic targeting strategy in FRTS3, although there is only one FRTS3 family known to date.

In other forms of RFS, where there is general mitochondrial dysfunction, achieving the opposite by increasing protein import may be a therapeutic option. Thus, the FDA-approved mitochondrial protein import stimulator sodium pyrithione has recently been shown to improve mitochondrial bioenergetics in Leigh patients [87]. This might also be relevant for acquired forms of RFS that are associated with ATP deficiency 
and/or oxidative phosphorylation defects, e.g. aminoglycosides and valproic acid associated RFS.

\subsubsection{Anti-oxidant therapy for RFSs}

The use of anti-oxidants like sirtuins and SS-peptides, MitoQ, and plastoquinone analogues and stanniocalcin-1 have also been suggested as potential therapeutical agents for RFS [88].

In addition, due to their nature of boosting the fatty acid oxidation, anti-oxidants like carnitine, fibrates and poly unsaturated fatty acids in form of a specific ketogenic diet could be investigated in the future as a potential treatment option for specific forms of RFS, like valproic acid induced RFS. These type of RFS have been shown to have inhibited fatty acid oxidation master-regulators like peroxisome proliferatoractivated receptor-alpha activity or PGC-1alpha, leading to deficient fatty acid oxidation $[89,90]$.

\subsubsection{Anti-apoptotic therapy for fumaric acid ester induced RFS, Tyrosinemia type I and Cystinosis}

Mitochondrial drug targeting to prevent apoptosis from happening has the potential to be used in RFS forms triggered by apoptosis, such as tyrosinemia type I, cystinosis, light-chain proximal tubulopathy or fumaric acid ester associated RFS. To this end caspase inhibitors can be used A good candidate that was proven successfully in a mouse model for fumaric acid ester associated proximal tubulopathy is the anti-apoptotic caspase inhibitor YVAD [91]. Other caspase 
inhibitors with clinically approved status that could potentially be used are: EmricasaN for which a clinical trial is ongoing for non-alcoholic steatohepatitis fibrosis and IDN-6556 in phase 2 clinical trial for Hepatitis C.

\subsection{4 mTORC stimulation}

Very recently a novel drug target for RFS has surfaced in a study published by Grahammer and co-workers [92]. The deficiency of mTORC1, an important regulator of lipid metabolism, was shown in a mouse model, to lead to a renal FS with reduced expression of PGC1-alpha, a key regulator of mitochondrial fatty acid oxidation [90]. The development of specific drugs targeting mTORC1 continues to grow, mainly for specific forms of cancer, including renal cell carcinoma, based on its function as a nutrient, redox, oxygen sensor and as an important stimulant for protein synthesis. Its activity is up-regulated by the amino acid leucine and its derivative beta hydroxyl beta methylbutyrate. The current knowledge supports the hypothesis that the stimulation of mTORC1 by amino acids like amino-acid-directed therapies may provide a mitochondrial-directed therapeutic approach for RFS [93].

\subsubsection{RNA silencing in MODY1 with RFS, FRTS1, FRTS3, and acquired forms of RFS}

Recently RNA silencing has been successfully used to develop novel management strategies, like for instance the use of the FDA-approved mipomersen, an apolipoprotein B synthesis inhibitor to lower LDL cholesterol in patients with homozygous familial hypercholesterolaemia. RNA silencing shows potential 
applicability in future clinical trials for the down-regulation of the disease specific alleles in dominant genetic diseases, in this way allowing the on-going functionality of the wild type allele. So far this has only been demonstrated using disease models [94]. This approach could then be used for FRTS1, FRTS3, and MODY1 with renal Fanconi syndrome giving the dominant nature of the inheritance.

Recently a novel target for a RNA silencing therapeutic approach in RFS emerged as the MicroRNA Mir21. This microRNA appeared to be a novel biomarker for proximal tubulopathies underlying AKI [95]. These novel findings, interestingly, point towards an important role of Mir21 in regulating metabolic activity in epithelial cells, in particular of lipid metabolism [96], as well as apoptosis related genes [95, 97], which are important pathways that are affected in several forms of RFS [98]. Mir21 could therefore be considered as an outstanding candidate to develop novel antisense therapeutics (antagomirs and mimics) for acquired forms of RFS in which these pathways are affected: tyrosinemia type I [85], cystinosis [99] and fumaric acid ester associated RFS [100]. This could also be the therapeutical target for RFS with defective fatty acid oxidation pathways.

\subsection{Conclusion}

Unequivocally clinicians and researchers are increasingly aware of the impact of RFS. Although the area of the treatment is at the moment the most disappointing, new experimental approaches and more testing of novel and existing therapeutic agents to will decipher potential model systems for RFS. 
Moreover, understanding of the impact of mitochondria and its relevance in the area of RFS hold much promise for future development of novel therapeutics for this complex class of diseases.

Our understanding of the pathogenesis of RFS will continue to improve also by unravelling the pathomechanism for the mono-genetic RFS FRTS2, and other families, where the causative genetic component has not yet been identified.

In this manuscript we discussed several potential future options for therapy in specific types of RFS.

- Targeting protein import problems in ATP deficiency related RFS

- Anti-apoptotic therapy for fumaric acid ester induced RFS, tyrosinemia type I and cystinosis

- RNA silencing in MODY1 with RFS, FRTS1, FRTS3, and acquired forms of RFS 
Table 1: Overview of different types of renal Fanconi syndrome

\begin{tabular}{|c|c|c|c|c|}
\hline Name & OMIM & Gene & Inheritance & Other symptoms \\
\hline $\begin{array}{l}\text { Cystinosis } \\
\text { (infantile) }\end{array}$ & 219800 & CTNS & AR & $\begin{array}{l}\text { Corneal cystine crystals, poor } \\
\text { growth, rickets, CKD and ESRF }\end{array}$ \\
\hline $\begin{array}{l}\text { Fanconi-Bickel } \\
\text { Syndrome }\end{array}$ & 227810 & $\begin{array}{l}\text { GLUT2 } \\
(\text { SLC2A2) }\end{array}$ & AR & $\begin{array}{l}\text { Glycogen storage disease, } \\
\text { hypoglycemia }\end{array}$ \\
\hline Tyrosinemia Type 1 & 276700 & $\mathrm{FAH}$ & AR & $\begin{array}{l}\text { Progressive liver disease, liver } \\
\text { cancer }\end{array}$ \\
\hline Galactosemia & 230400 & GALT & AR & $\begin{array}{l}\text { Liver dysfunction, jaundice, } \\
\text { encephalopathy, sepsis }\end{array}$ \\
\hline $\begin{array}{l}\text { Hereditary Fructose } \\
\text { Intolerance }\end{array}$ & 229600 & ALDOB & AR & $\begin{array}{l}\text { Hypoglycemia, vomiting, liver } \\
\text { disease }\end{array}$ \\
\hline Wilson Disease & 277900 & ATP7B & AR & $\begin{array}{l}\text { Liver disease, neurological } \\
\text { abnormalities, Kayser-Fleischer } \\
\text { rings }\end{array}$ \\
\hline Lowe Syndrome & 309000 & OCRL & XLR & $\begin{array}{l}\text { Cataract, mental impairment, } \\
\text { rickets }\end{array}$ \\
\hline Dent I & 300009 & CLCN5 & XLR & Male predominance \\
\hline Dent II & 300555 & OCRL & XLR & Male predominance \\
\hline MODY 1 & 125850 & HNF4A & $A D$ & $\begin{array}{l}\text { Neonatal hyperinsulinism, } \\
\text { maturity-onset of diabetes in the } \\
\text { young }\end{array}$ \\
\hline FRTS1 & 134600 & $?$ & $A D$ & Chronic kidney disease \\
\hline FRTS2 & 613388 & SLC34A1 & AR & Mainly phosphaturia \\
\hline FRTS3 & 615605 & EHHADH & $A D$ & No chronic kidney disease \\
\hline
\end{tabular}


Figure 1: Schematic of renal proximal tubular cell with key transepithelial transport systems.

\section{* Proximal Tubule Cell}

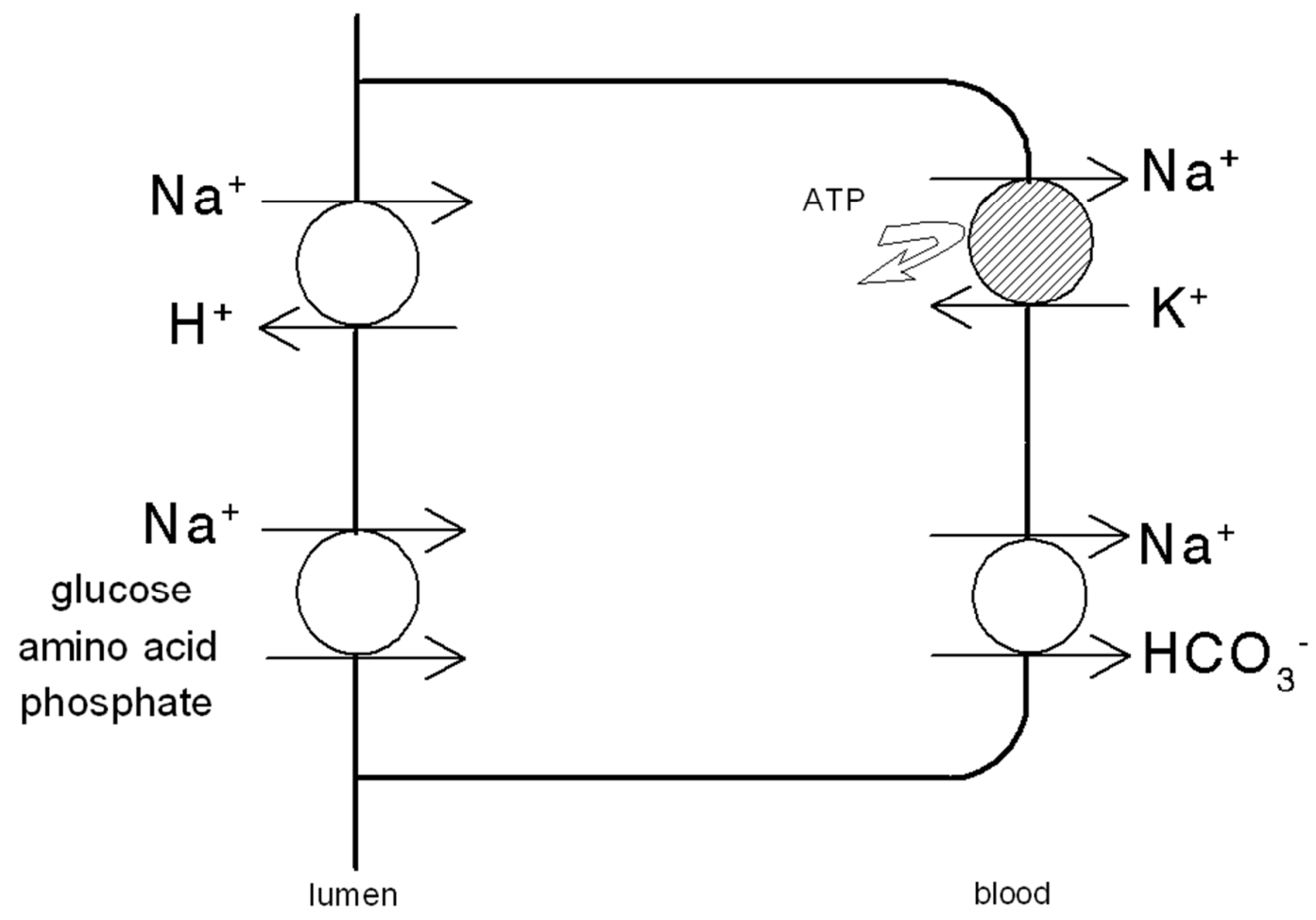

34

35

36

37

38

39

40

41

42

43

44

45

46

47

48

49

50

51

52

53

54

55

56

57

58

59

60 
Figure 2: Potential therapeutic solutions linked to restoration of mitochondrial energy metabolism in renal Fanconi syndromes.

Drugs could be developed against $\operatorname{mTORC1}$, which has recently been linked to causing a renal Fanconi-like syndrome in a mouse model deficient of mTORC1. Furthermore DECA-associated therapeutics could be developed for renal Fanconi syndromes, in particular for FRTS3, since it is an effective FDA-approved mitochondrial targeting agent. Also antisense-Mir21 could be considered an important target since Mir-21 is considered a biomarker for $\mathrm{AKI}$, and it has been shown to be an effective treatment for restoration of kidney function in Alport nephropathy. Other important therapeutic interventions could be fibrates and carnitine supplementation for acquired forms of renal Fanconi syndrome.

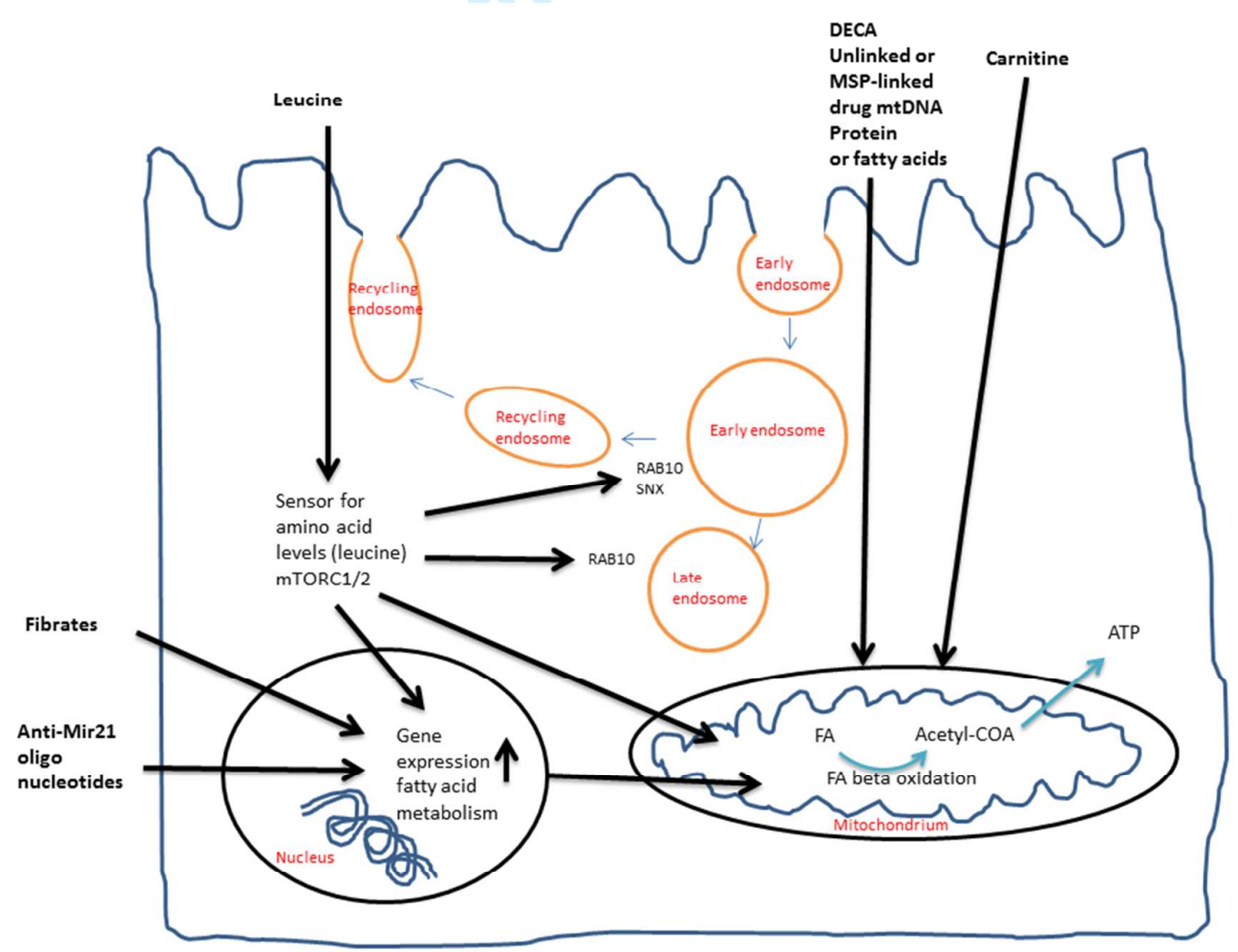


References

1. Kleta R, Gahl WA (2002) Cystinosis: antibodies and healthy bodies. J Am Soc Nephrol 13:2189-2191.

2. de Toni G (1933) Remarks on the Relationship between Renal Rickets (Renal Dwarfism) and Renal Diabetes. Acta Paediatrica 16:479-484.

3. Debre R, Marie J, Cleret F, Messimy R (1934) Rachitisme tardif coexistant avec une Nephrite chronique et une Glycosurie. Archive de Medicine des Enfants 37:597-606.

4. Kleta R, Bockenhauer D (2006) Bartter syndromes and other salt-losing tubulopathies. Nephron Physiol 104:p73-80.

5. Avner ED, Harmon WE, Niaudet P, Yoshikawa N (2009) Pediatric Nephrology. Springer.

6. Klootwijk ED, Reichold M, Unwin RJ, Kleta R, Warth R, Bockenhauer D (2015) Renal Fanconi syndrome: taking a proximal look at the nephron. Nephrol Dial Transplant 30:1456-1460.

7. Rose BD (1977) Clinical physiology of acid-base and electrolyte disorders. McGraw-Hill.

8. Christensen El, Birn H, Storm T, Weyer K, Nielsen R (2012) Endocytic receptors in the renal proximal tubule. Physiology (Bethesda, Md) 27:223-236.

9. Hou J (2014) The kidney tight junction (Review). Int J Mol Med 34:1451-1457.

10. Wilmes A, Aschauer L, Limonciel A, Pfaller W, Jennings P (2014) Evidence for a role of claudin 2 as a proximal tubular stress responsive paracellular water channel. Toxicol Appl Pharmacol 279:163-172.

11. Plumb LA, van't Hoff W, Kleta R, Reid C, Ashton E, Samuels M, Bockenhauer D (2016) Renal apnoea: extreme disturbance of homoeostasis in a child with Bartter syndrome type IV. Lancet 388:631-632.

12. Igarashi T, Sekine T, Inatomi J, Seki G (2002) Unraveling the molecular pathogenesis of isolated proximal renal tubular acidosis. J Am Soc Nephrol 13:2171-2177.

13. Boron WF (2006) Acid-base transport by the renal proximal tubule. J Am Soc Nephrol 17:2368-2382.

14. Seki G, Nakamura M, Suzuki M, Satoh N, Horita S (2015) Species differences in regulation of renal proximal tubule transport by certain molecules. World $\mathrm{J}$ Nephrol 4:307-312.

15. Magen D, Berger L, Coady MJ, Ilivitzki A, Militianu D, Tieder M, Selig S, Lapointe JY, Zelikovic I, Skorecki K (2010) A loss-of-function mutation in NaPi-Ila and renal Fanconi's syndrome. N Engl J Med 362:1102-1109.

16. Biber J, Hernando N, Forster I, Murer H (2009) Regulation of phosphate transport in proximal tubules. Pflugers Arch 458:39-52.

17. Walton RJ, Bijvoet OL (1977) A simple slide-rule method for the assessment of renal tubular reaborption of phosphate in man. Clin Chim Acta 81:273-276.

18. Dickson LE, Wagner MC, Sandoval RM, Molitoris BA (2014) The proximal tubule and albuminuria: really! J Am Soc Nephrol 25:443-453.

19. Christensen El, Birn H (2002) Megalin and cubilin: multifunctional endocytic receptors. Nat Rev Mol Cell Biol 3:256-266.

20. Dhooria GS, Bains HS (2014) Nephrotic range proteinuria as a presenting feature of classical nephropathic cystinosis. Indian J Pediatr 81:712-714. 
21. O'Brien K, Hussain N, Warady BA, Kleiner DE, Kleta R, Bernardini I, Heller T, Gahl WA (2006) Nodular regenerative hyperplasia and severe portal hypertension in cystinosis. Clin Gastroenterol Hepatol 4:387-394.

22. Emma F, Nesterova G, Langman C, Labbe A, Cherqui S, Goodyer P, Janssen MC, Greco M, Topaloglu R, Elenberg E, Dohil R, Trauner D, Antignac C, Cochat P, Kaskel F, Servais A, Wuhl E, Niaudet P, Van't Hoff W, Gahl W, Levtchenko E (2014) Nephropathic cystinosis: an international consensus document. Nephrol Dial Transplant 29 Suppl 4:iv87-94.

23. Kleta R, Kaskel F, Dohil R, Goodyer P, Guay-Woodford LM, Harms E, Ingelfinger JR, Koch VH, Langman CB, Leonard MB, Mannon RB, Sarwal M, Schneider JA, Skovby F, Sonies BC, Thoene JG, Trauner DA, Gahl WA, Diseases NIHOoR (2005) First NIH/Office of Rare Diseases Conference on Cystinosis: past, present, and future. Pediatr Nephrol 20:452-454.

24. Gahl WA, Thoene JG, Schneider JA (2002) Cystinosis. N Engl J Med 347:111-121.

25. Bendavid C, Kleta R, Long R, Ouspenskaia M, Muenke M, Haddad BR, Gahl WA (2004) FISH diagnosis of the common 57-kb deletion in CTNS causing cystinosis. Hum Genet 115:510-514.

26. Levtchenko E, van den Heuvel L, Emma F, Antignac C (2014) Clinical utility gene card for: cystinosis. Eur J Hum Genet 22.

27. Topaloglu R, Vilboux T, Coskun T, Ozaltin F, Tinloy B, Gunay-Aygun M, Bakkaloglu A, Besbas N, van den Heuvel L, Kleta R, Gahl WA (2012) Genetic basis of cystinosis in Turkish patients: a single-center experience. Pediatr Nephrol 27:115-121.

28. Kleta R, Anikster Y, Lucero C, Shotelersuk V, Huizing M, Bernardini I, Park M, Thoene J, Schneider J, Gahl WA (2001) CTNS mutations in African American patients with cystinosis. Mol Genet Metab 74:332-337.

29. Cetinkaya I, Schlatter E, Hirsch JR, Herter P, Harms E, Kleta R (2002) Inhibition of $\mathrm{Na}(+)$-dependent transporters in cystine-loaded human renal cells: electrophysiological studies on the Fanconi syndrome of cystinosis. J Am Soc Nephrol 13:2085-2093.

30. Medlar A, Kleta R (2010) Cystinosis and mickey mouse. Nephrol Dial Transplant 25:1032-1033.

31. Gaide Chevronnay HP, Janssens V, Van Der Smissen P, N'Kuli F, Nevo N, Guiot Y, Levtchenko E, Marbaix E, Pierreux CE, Cherqui S, Antignac C, Courtoy PJ (2014) Time course of pathogenic and adaptation mechanisms in cystinotic mouse kidneys. J Am Soc Nephrol 25:1256-1269.

32. Galarreta Cl, Forbes MS, Thornhill BA, Antignac C, Gubler MC, Nevo N, Murphy MP, Chevalier RL (2015) The swan-neck lesion: proximal tubular adaptation to oxidative stress in nephropathic cystinosis. Am J Physiol Renal Physiol 308:F1155-1166.

33. Mahoney CP, Striker GE (2000) Early development of the renal lesions in infantile cystinosis. Pediatr Nephrol 15:50-56.

34. Greco M, Brugnara M, Zaffanello M, Taranta A, Pastore A, Emma F (2010) Long-term outcome of nephropathic cystinosis: a 20-year single-center experience. Pediatr Nephrol 25:2459-2467.

35. Gahl WA, Balog JZ, Kleta R (2007) Nephropathic cystinosis in adults: natural history and effects of oral cysteamine therapy. Ann Intern Med 147:242-250.

36. Kleta R (2006) A deeper look into cysteamine absorption for the treatment of cystinosis. J Pediatr 148:718-719. 
37. Sonies BC, Almajid P, Kleta R, Bernardini I, Gahl WA (2005) Swallowing dysfunction in 101 patients with nephropathic cystinosis: benefit of long-term cysteamine therapy. Medicine (Baltimore) 84:137-146.

38. Kleta R, Gahl WA (2004) Pharmacological treatment of nephropathic cystinosis with cysteamine. Expert Opin Pharmacother 5:2255-2262.

39. Kleta R, Bernardini I, Ueda M, Varade WS, Phornphutkul C, Krasnewich D, Gahl WA (2004) Long-term follow-up of well-treated nephropathic cystinosis patients. J Pediatr 145:555-560.

40. Rega LR, Polishchuk E, Montefusco S, Napolitano G, Tozzi G, Zhang J, Bellomo F, Taranta A, Pastore A, Polishchuk R, Piemonte F, Medina DL, Catz SD, Ballabio A, Emma F (2016) Activation of the transcription factor EB rescues lysosomal abnormalities in cystinotic kidney cells. Kidney Int 89:862873.

41. Santer R, Steinmann B, Schaub J (2002) Fanconi-Bickel syndrome--a congenital defect of facilitative glucose transport. Curr Mol Med 2:213-227.

42. Santer R, Groth S, Kinner M, Dombrowski A, Berry GT, Brodehl J, Leonard JV, Moses S, Norgren S, Skovby F, Schneppenheim R, Steinmann B, Schaub $J$ (2002) The mutation spectrum of the facilitative glucose transporter gene SLC2A2 (GLUT2) in patients with Fanconi-Bickel syndrome. Hum Genet 110:21-29.

43. Santer R, Schneppenheim R, Suter D, Schaub J, Steinmann B (1998) Fanconi-Bickel syndrome--the original patient and his natural history, historical steps leading to the primary defect, and a review of the literature. Eur J Pediatr 157:783-797.

44. Maiorana A, Malamisura M, Emma F, Boenzi S, Di Ciommo VM, Dionisi-Vici C (2014) Early effect of NTBC on renal tubular dysfunction in hereditary tyrosinemia type 1. Mol Genet Metab 113:188-193.

45. Sun MS, Hattori S, Kubo S, Awata H, Matsuda I, Endo F (2000) A mouse model of renal tubular injury of tyrosinemia type 1: development of de Toni Fanconi syndrome and apoptosis of renal tubular cells in Fah/Hpd double mutant mice. J Am Soc Nephrol 11:291-300.

46. Weinberg AG, Mize CE, Worthen HG (1976) The occurrence of hepatoma in the chronic form of hereditary tyrosinemia. J Pediatr 88:434-438.

47. Santra S, Preece MA, Hulton SA, McKiernan PJ (2008) Renal tubular function in children with tyrosinaemia type I treated with nitisinone. J Inherit Metab Dis 31:399-402.

48. Hamilton AJ, Bingham C, McDonald TJ, Cook PR, Caswell RC, Weedon MN, Oram RA, Shields BM, Shepherd M, Inward CD, Hamilton-Shield JP, Kohlhase J, Ellard S, Hattersley AT (2014) The HNF4A R76W mutation causes atypical dominant Fanconi syndrome in addition to a beta cell phenotype. J Med Genet 51:165-169.

49. Bosch AM (2006) Classical galactosaemia revisited. J Inherit Metab Dis 29:516-525.

50. Roberts EA, Sarkar B (2008) Liver as a key organ in the supply, storage, and excretion of copper. Am J Clin Nutr 88:851S-854S.

51. Selvan C, Thukral A, Chakraborthy PP, Bhattacharya R, Roy A, Goswani S, Meher D, Ghosh S, Mukhopadhyay S, Chowdhury S (2012) Refractory rickets due to Fanconi's Syndrome secondary to Wilson's disease. Indian $\mathrm{J}$ Endocrinol Metab 16:S399-401. 
52. Bouteldja N, Timson DJ (2010) The biochemical basis of hereditary fructose intolerance. J Inherit Metab Dis 33:105-112.

53. Zhang X, Jefferson AB, Auethavekiat V, Majerus PW (1995) The protein deficient in Lowe syndrome is a phosphatidylinositol-4,5-bisphosphate 5phosphatase. Proc Natl Acad Sci U S A 92:4853-4856.

54. Levin-laina N, Dinour D (2012) Renal disease with OCRL1 mutations: Dent-2 or Lowe syndrome? J Pediatr Genet 1:3-5.

55. Lewis RA, Nussbaum RL, Brewer ED (1993) Lowe Syndrome. In: Pagon RA, Adam MP, Ardinger HH, Bird TD, Dolan CR, Fong CT, Smith RJH, Stephens K (eds) GeneReviews(R). University of Washington, Seattle, Seattle (WA).

56. Böckenhauer D, Bökenkamp A, Nuutinen M, Unwin R, van't Hoff W, Sirimanna T, Vrljicak K, Ludwig M (2012) Novel OCRL mutations in patients with Dent-2 disease. J Pediatr Genet 1:15-23.

57. Gillooly DJ, Stenmark H (2001) Cell biology. A lipid oils the endocytosis machine. Science (New York, NY) 291:993-994.

58. Choudhury R, Diao A, Zhang F, Eisenberg E, Saint-Pol A, Williams C, Konstantakopoulos A, Lucocq J, Johannes L, Rabouille C, Greene LE, Lowe M (2005) Lowe syndrome protein OCRL1 interacts with clathrin and regulates protein trafficking between endosomes and the trans-Golgi network. Mol Biol Cell 16:3467-3479.

59. Bokenkamp A, Ludwig M (2016) The oculocerebrorenal syndrome of Lowe: an update. Pediatr Nephrol in press.

60. Kleta R (2008) Fanconi or not Fanconi? Lowe syndrome revisited. Clin J Am Soc Nephrol 3:1244-1245.

61. Sethi SK, Lunardi J, Kabra M, Deka D, Bagga A (2010) Antenatal diagnosis of Lowe syndrome. Clin Exp Nephrol 14:296-297.

62. Grand T, L'Hoste S, Mordasini D, Defontaine N, Keck M, Pennaforte T, Genete M, Laghmani K, Teulon J, Lourdel S (2011) Heterogeneity in the processing of CLCN5 mutants related to Dent disease. Hum Mutat 32:476483.

63. Devuyst O, Thakker RV (2010) Dent's disease. Orphanet J Rare Dis 5:28.

64. Norden AG, Lapsley M, Igarashi T, Kelleher CL, Lee PJ, Matsuyama T, Scheinman SJ, Shiraga H, Sundin DP, Thakker RV, Unwin RJ, Verroust P, Moestrup SK (2002) Urinary megalin deficiency implicates abnormal tubular endocytic function in Fanconi syndrome. J Am Soc Nephrol 13:125-133.

65. Hoopes RR, Jr., Shrimpton AE, Knohl SJ, Hueber P, Hoppe B, Matyus J, Simckes A, Tasic V, Toenshoff B, Suchy SF, Nussbaum RL, Scheinman SJ (2005) Dent Disease with mutations in OCRL1. Am J Hum Genet 76:260-267.

66. Hichri H, Rendu J, Monnier N, Coutton C, Dorseuil O, Poussou RV, Baujat G, Blanchard A, Nobili F, Ranchin B, Remesy M, Salomon R, Satre V, Lunardi J (2011) From Lowe syndrome to Dent disease: correlations between mutations of the OCRL1 gene and clinical and biochemical phenotypes. Hum Mutat 32:379-388.

67. Recker F, Zaniew M, Bockenhauer D, Miglietti N, Bokenkamp A, Moczulska A, Rogowska-Kalisz A, Laube G, Said-Conti V, Kasap-Demir B, Niemirska A, Litwin M, Siten G, Chrzanowska KH, Krajewska-Walasek M, Sethi SK, Tasic V, Anglani F, Addis M, Wasilewska A, Szczepanska M, Pawlaczyk K, Sikora $P$, Ludwig M (2015) Characterization of 28 novel patients expands the mutational and phenotypic spectrum of Lowe syndrome. Pediatr Nephrol 30:931-943. 
68. Lichter-Konecki U, Broman KW, Blau EB, Konecki DS (2001) Genetic and physical mapping of the locus for autosomal dominant renal Fanconi syndrome, on chromosome 15q15.3. Am J Hum Genet 68:264-268.

69. Tieder M, Arie R, Modai D, Samuel R, Weissgarten J, Liberman UA (1988) Elevated serum 1,25-dihydroxyvitamin $D$ concentrations in siblings with primary Fanconi's syndrome. N Engl J Med 319:845-849.

70. Bergwitz C, Roslin NM, Tieder M, Loredo-Osti JC, Bastepe M, Abu-Zahra H, Frappier D, Burkett K, Carpenter TO, Anderson D, Garabedian M, Sermet I, Fujiwara TM, Morgan K, Tenenhouse HS, Juppner H (2006) SLC34A3 mutations in patients with hereditary hypophosphatemic rickets with hypercalciuria predict a key role for the sodium-phosphate cotransporter $\mathrm{NaPi-Ilc}$ in maintaining phosphate homeostasis. Am J Hum Genet 78:179192.

71. Schlingmann KP, Ruminska J, Kaufmann M, Dursun I, Patti M, Kranz B, Pronicka E, Ciara E, Akcay T, Bulus D, Cornelissen EA, Gawlik A, Sikora P, Patzer L, Galiano M, Boyadzhiev V, Dumic M, Vivante A, Kleta R, Dekel B, Levtchenko E, Bindels RJ, Rust S, Forster IC, Hernando N, Jones G, Wagner CA, Konrad M (2016) Autosomal-Recessive Mutations in SLC34A1 Encoding Sodium-Phosphate Cotransporter 2A Cause Idiopathic Infantile Hypercalcemia. J Am Soc Nephrol 27:604-614.

72. Klootwijk ED, Reichold M, Helip-Wooley A, Tolaymat A, Broeker C, Robinette SL, Reinders J, Peindl D, Renner K, Eberhart K, Assmann N, Oefner PJ, Dettmer K, Sterner C, Schroeder J, Zorger N, Witzgall R, Reinhold SW, Stanescu HC, Bockenhauer D, Jaureguiberry G, Courtneidge H, Hall AM, Wijeyesekera AD, Holmes E, Nicholson JK, O'Brien K, Bernardini I, Krasnewich DM, Arcos-Burgos M, Izumi Y, Nonoguchi H, Jia Y, Reddy JK, Ilyas M, Unwin RJ, Gahl WA, Warth R, Kleta R (2014) Mistargeting of peroxisomal EHHADH and inherited renal Fanconi's syndrome. $\mathrm{N}$ Engl J Med 370:129-138.

73. Assmann N, Dettmer K, Simbuerger JM, Broeker C, Nuernberger N, Renner K, Courtneidge H, Klootwijk ED, Duerkop A, Hall A, Kleta R, Oefner PJ, Reichold M, Reinders J (2016) Renal Fanconi Syndrome Is Caused by a Mistargeting-Based Mitochondriopathy. Cell Rep 15:1423-1429.

74. Balaban RS, Mandel LJ (1988) Metabolic substrate utilization by rabbit proximal tubule. An NADH fluorescence study. Am J Physiol 254:F407-416.

75. Ciarimboli G, Holle SK, Vollenbrocker B, Hagos Y, Reuter S, Burckhardt G, Bierer S, Herrmann E, Pavenstadt H, Rossi R, Kleta R, Schlatter E (2011) New clues for nephrotoxicity induced by ifosfamide: preferential renal uptake via the human organic cation transporter 2. Mol Pharm 8:270-279.

76. Rossi R, Pleyer J, Schafers P, Kuhn N, Kleta R, Deufel T, Jurgens H (1999) Development of ifosfamide-induced nephrotoxicity: prospective follow-up in 75 patients. Med Pediatr Oncol 32:177-182.

77. Monnens L, Levtchenko E (2008) Evaluation of the proximal tubular function in hereditary renal Fanconi syndrome. Nephrol Dial Transplant 23:2719-2722.

78. Magnano L, Fernandez de Larrea C, Cibeira MT, Rozman M, Tovar N, Rovira M, Rosinol L, Blade J (2013) Acquired Fanconi syndrome secondary to monoclonal gammopathies: a case series from a single center. Clin Lymphoma Myeloma Leuk 13:614-618.

79. Saeki T, Nakajima A, Ito T, Takata T, Imai N, Yoshita K, Kabasawa H, Yamazaki H, Narita I (2016) Tubulointerstitial nephritis and Fanconi syndrome 
in a patient with primary Sjogren's syndrome accompanied by antimitochondrial antibodies: A case report and review of the literature. Mod Rheumatol in press.

80. Rossi R, Kleta R, Ehrich JH (1999) Renal involvement in children with malignancies. Pediatr Nephrol 13:153-162.

81. Kleta R, Blair SC, Bernardini I, Kaiser-Kupfer MI, Gahl WA (2004) Keratopathy of multiple myeloma masquerading as corneal crystals of ocular cystinosis. Mayo Clin Proc 79:410-412.

82. Hall AM, Bass P, Unwin RJ (2014) Drug-induced renal Fanconi syndrome. QJM 107:261-269.

83. Sirac C, Bridoux F, Essig M, Devuyst O, Touchard G, Cogne M (2011) Toward understanding renal Fanconi syndrome: step by step advances through experimental models. Contrib Nephrol 169:247-261.

84. Elmonem MA, Veys KR, Soliman NA, van Dyck M, van den Heuvel LP, Levtchenko E (2016) Cystinosis: a review. Orphanet J Rare Dis 11:47.

85. Endo F, Sun MS (2002) Tyrosinaemia type I and apoptosis of hepatocytes and renal tubular cells. J Inherit Metab Dis 25:227-234.

86. Miyata N, Steffen J, Johnson ME, Fargue S, Danpure CJ, Koehler CM (2014) Pharmacologic rescue of an enzyme-trafficking defect in primary hyperoxaluria 1. Proc Natl Acad Sci U S A 111:14406-14411.

87. Aiyar RS, Bohnert M, Duvezin-Caubet S, Voisset C, Gagneur J, Fritsch ES, Couplan E, von der Malsburg K, Funaya C, Soubigou F, Courtin F, Suresh S, Kucharczyk R, Evrard J, Antony C, St Onge RP, Blondel M, di Rago JP, van der Laan M, Steinmetz LM (2014) Mitochondrial protein sorting as a therapeutic target for ATP synthase disorders. Nat Commun 5:5585.

88. Hall AM, Schuh CD (2016) Mitochondria as therapeutic targets in acute kidney injury. Curr Opin Nephrol Hypertens 25:355-362.

89. Silva MF, Aires CC, Luis PB, Ruiter JP, L IJ, Duran M, Wanders RJ, Tavares de Almeida I (2008) Valproic acid metabolism and its effects on mitochondrial fatty acid oxidation: a review. J Inherit Metab Dis 31:205-216.

90. Portilla D, Dai G, McClure T, Bates L, Kurten R, Megyesi J, Price P, Li S (2002) Alterations of PPARalpha and its coactivator PGC-1 in cisplatininduced acute renal failure. Kidney Int 62:1208-1218.

91. Kubo S, Sun M, Miyahara M, Umeyama K, Urakami K, Yamamoto T, Jakobs C, Matsuda I, Endo F (1998) Hepatocyte injury in tyrosinemia type 1 is induced by fumarylacetoacetate and is inhibited by caspase inhibitors. Proc Natl Acad Sci U S A 95:9552-9557.

92. Grahammer F, Ramakrishnan SK, Rinschen MM, Larionov AA, Syed M, Khatib H, Roerden M, Sass JO, Helmstaedter M, Osenberg D, Kuhne L, Kretz O, Wanner N, Jouret F, Benzing T, Artunc F, Huber TB, Theilig F (2016) mTOR Regulates Endocytosis and Nutrient Transport in Proximal Tubular Cells. J Am Soc Nephrol in press.

93. Dodd KM, Tee AR (2012) Leucine and mTORC1: a complex relationship. Am J Physiol Endocrinol Metab 302:E1329-1342.

94. Klootwijk RD, Savelkoul PJ, Ciccone C, Manoli I, Caplen NJ, Krasnewich DM, Gahl WA, Huizing M (2008) Allele-specific silencing of the dominant disease allele in sialuria by RNA interference. FASEB J 22:3846-3852.

95. Li YF, Jing Y, Hao J, Frankfort NC, Zhou X, Shen B, Liu X, Wang L, Li R (2013) MicroRNA-21 in the pathogenesis of acute kidney injury. Protein Cell 4:813-819. 
96. Tsai WC, Hsu SD, Hsu CS, Lai TC, Chen SJ, Shen R, Huang Y, Chen HC, Lee CH, Tsai TF, Hsu MT, Wu JC, Huang HD, Shiao MS, Hsiao M, Tsou AP (2012) MicroRNA-122 plays a critical role in liver homeostasis and hepatocarcinogenesis. J Clin Invest 122:2884-2897.

97. Zhang A, Liu Y, Shen Y, Xu Y, Li X (2011) miR-21 modulates cell apoptosis by targeting multiple genes in renal cell carcinoma. Urology 78:474 e413-479.

98. Chau BN, Xin C, Hartner J, Ren S, Castano AP, Linn G, Li J, Tran PT, Kaimal V, Huang X, Chang AN, Li S, Kalra A, Grafals M, Portilla D, MacKenna DA, Orkin SH, Duffield JS (2012) MicroRNA-21 promotes fibrosis of the kidney by silencing metabolic pathways. Sci Transl Med 4:121ra118.

99. Thoene JG (2007) A review of the role of enhanced apoptosis in the pathophysiology of cystinosis. Mol Genet Metab 92:292-298.

100. Rostami Yazdi M, Mrowietz U (2008) Fumaric acid esters. Clin Dermatol 26:522-526. 